\title{
Aortic dissection-induced acute flaccid paraplegia treated with cerebrospinal fluid drainage
}

\author{
Eduardo Leal Adam ${ }^{\mathrm{a}}$, Henrique Lane Staniak ${ }^{\mathrm{a}}$, Rodolfo Sharovsky ${ }^{\mathrm{b}}$, Adriano Ferreira da Silva ${ }^{\mathrm{b}}$, \\ Cláudio Campi de Castro ${ }^{b}$, Márcio Sommer Bittencourta
}

Adam EL, Staniak HL, Sharovsky R, Silva AF, Castro CC, Bittencourt MS. Aortic dissection-induced acute flaccid paraplegia treated with cerebrospinal fluid drainage. Autopsy Case Rep [Internet]. 2012;2(1):25-28. http://dx.doi.org/10.4322/acr.2012.004

\section{ABSTRACT}

Acute aortic dissection is a life-threatening event in which prompt and correct diagnosis is associated with better outcomes. In most cases, there is chest or back pain. However, in rare cases, patients have little or no pain and other symptoms are more conspicuous at presentation. The autors reports the case of a 47-year-old female patient who sought medical attention for sudden-onset paraplegia. The physical examination was normal except for bilateral lower limb flaccid paralysis, with abolition of deep tendon reflexes and paraesthesia in both feet. Computed tomography showed aortic dissection, with partial thrombosis of the false lumen, starting after the emergence of the left subclavian artery and extending, toward the bifurcation of the aorta, to the left iliac artery. After cerebrospinal fluid drainage, the evolution was favorable.

Keywords: Aortic diseases; Aneurysm, dissecting; Paraplegia; Cerebrospinal fluid.

\section{CASE REPORT}

A 47-year-old female patient presented to the emergency room (ER) complaining of sudden-onset paraplegia for the last 30 minutes, accompanied by discrete back pain. On initial physical examination, blood pressure was $140 / 90 \mathrm{mmHg}$ in both arms, heart rate was $72 \mathrm{bpm}$, pulses were palpable and symmetrical. The neurologic examination showed bilateral lower limb flaccid paralysis, with abolition of deep tendon reflexes, accompanied by paresthesias in both feet. The remainder of the physical exam and the admission electrocardiogram were normal. Her medical history was unremarkable, except for having been a smoker. Although pain was not the most prominent feature at presentation, aortic dissection with neurological symptoms was suspected as a diagnostic possibility for acute flaccid paraplegia.
Contrast computed tomography (CT) showed a Stanford Type B aortic dissection with partial thrombosis of the false lumen, starting immediately after the emergence of the left subclavian artery, extending, in the direction the bifurcation of the aorta, to the left iliac artery. The supra-aortic and abdominal branches were not affected by the dissection (Figures 1-3).

After the initial medical treatment with betablockers and oxygen, the patient was transferred to a tertiary care hospital, where the treatment adopted consisted in drainage of the cerebrospinal fluid (CSF) through the insertion of a lumbar catheter. The aortic dissection was treated conservatively due to the false lumen thrombosis. The patient

\footnotetext{
a Department of Internal Medicine - Hospital Universitário, Universidade de São Paulo, São Paulo/SP - Brazil.

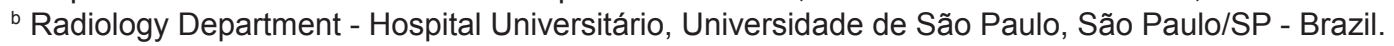

Copyright $\odot 2012$ Autopsy and Case Reports - This is an Open Access article distributed of terms of the Creative Commons Attribution NonCommercial License (http://creativecommons.org/licenses/by/3.0/) which permits unrestricted non-commercial use, distribution, and reproduction in any médium provided article is properly cited. 


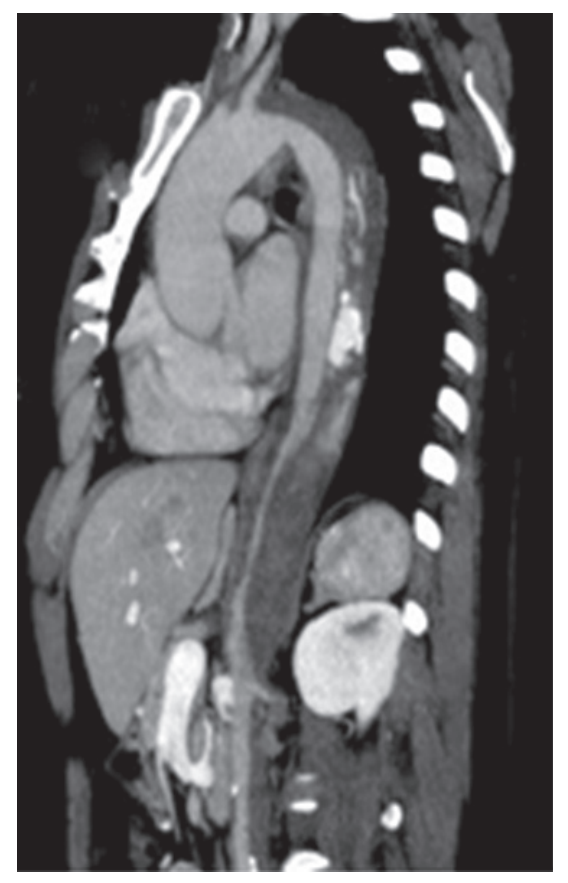

Figure 1 - Multidetector CT of the thorax and abdomen. Sagittal reformatted images. Reconstruction of the entire aorta showing the dissection and partial thrombus from the subclavian to the iliac artery.

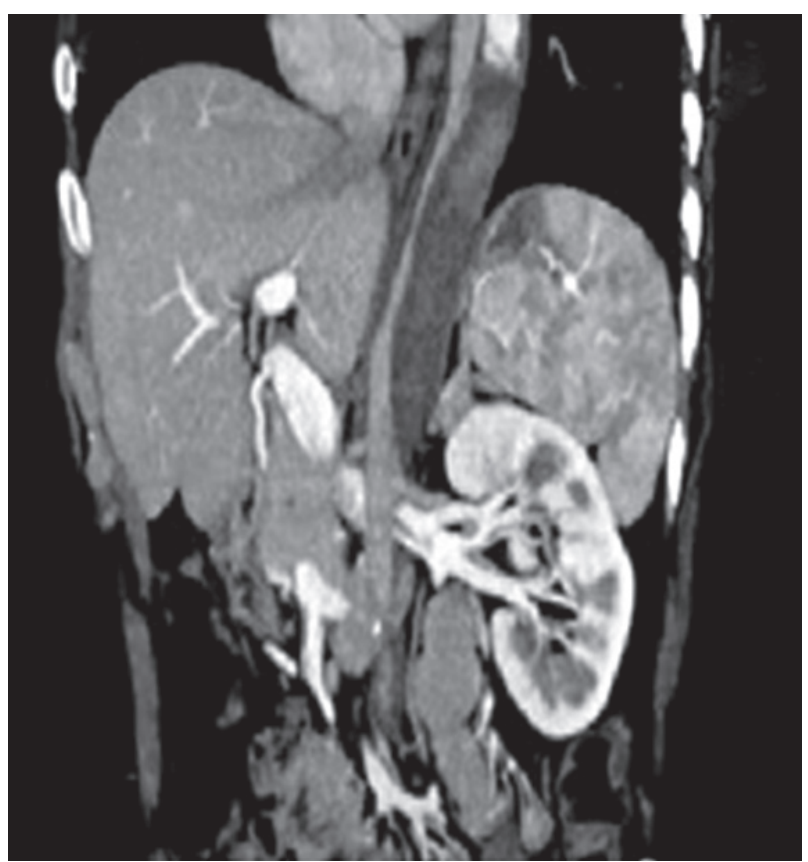

Figure 2 - Multidetector CT of the abdomen. Coronal reformatted images of the abdominal aorta, showing the narrowed lumen of the abdominal aorta.

presented progressive neurological improvement during the first few days after initiation of the proposed treatment, achieving and maintaining grade 4 muscular strength in the lower extremities. The lumbar catheter was removed three days after

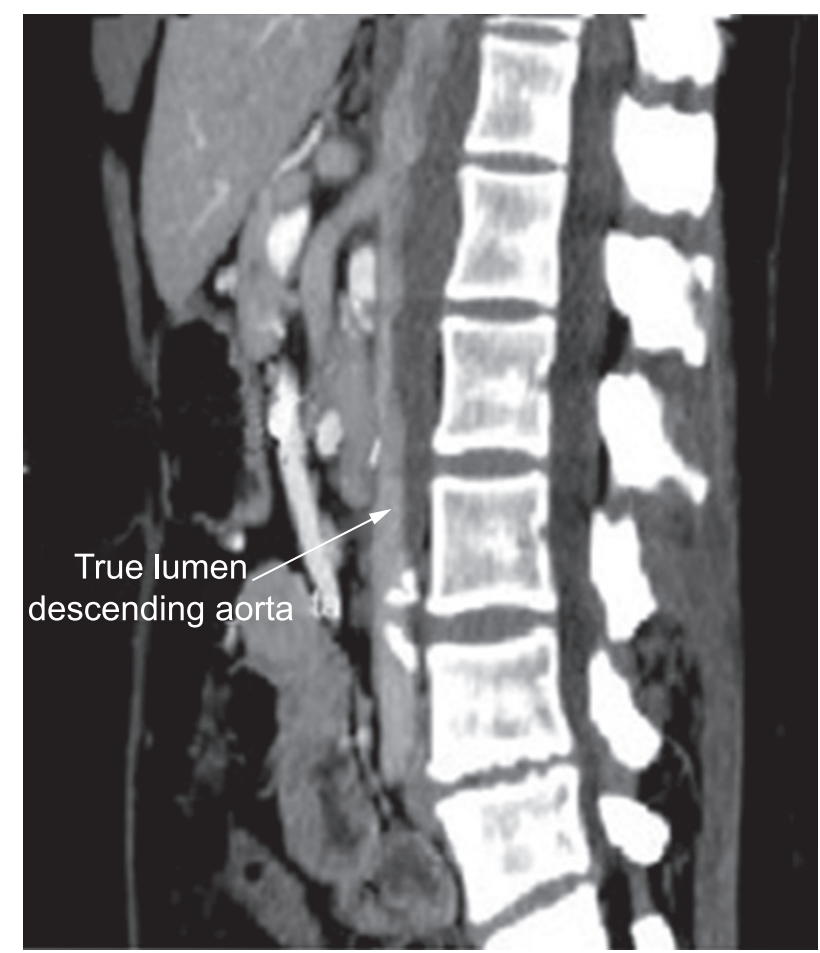

Figure 3 - Multidetector CT of the abdomen. Sagittal reformatted images of the abdominal aorta, highlighting the predominance of the dissection in the posterior portion, where the spinal cord branches typically emerge.

the puncture. A follow-up CT performed at one week after admission showed that the extent of the dissection remained unchanged. The patient was discharged to outpatient medical and physical therapy follow-up.

\section{DISCUSSION}

Acute aortic dissection is a cardiovascular emergency defined as the development of a tear in the aortic intima, followed by the passage of blood through the aortic media, creating a false lumen. ${ }^{1}$ It is a life-threatening event in which it is extremely important that a prompt and accurate diagnosis be made in the ER. Although chest or back pain is present in most cases, some patients can have little or no pain and other symptoms can be more conspicuous at presentation. In up to $95 \%$ of cases, the clinical presentation is characterized by severe chest or back pain, depending on whether the ascending or descending aorta is involved. When severe pain is absent at the initial presentation, the diagnosis can be challenging, leading to poor outcomes compared with those observed in patients presenting with painful aortic dissections. ${ }^{2}$ 
The development of a false lumen from the subclavian artery to the iliac arteries can lead to limb ischemia, producing the classically described asymmetry of pulses and blood pressure. However, when there is involvement of the aortic branches responsible for the blood supply to the intrathoracic or abdominal viscera, the diagnosis can only be clinically suspected due to the consequences of end-organ hypoperfusion, such as renal failure, mesenteric ischemia, acute myocardial infarction, and spinal cord ischemia leading to paraplegia, ${ }^{3,4}$ as in the case described here.

The differential diagnosis of paraplegia is wide, including infectious, degenerative, toxicmetabolic, and vascular disorders, as well as spinal cord injury and neoplasms. ${ }^{5}$ Although various myelopathies can have a sudden onset, this form of presentation suggests, and should always raise the diagnostic possibility of, an acute vascular event such as aortic dissection, epidural hematoma, arteriovenous malformation, embolism, and vasculitides. ${ }^{6}$ Paraplegia occurs in $2-8 \%$ of aortic dissections, sometimes without pain, thereby requiring a high level of suspicion for diagnosis. Once suspected, the diagnosis must be confirmed, whenever possible, by an imaging study. In the ER setting, CT is typically available and therefore frequently used.

In the current guidelines, there are no specific recommendations regarding the treatment of spinal cord ischemia in acute aortic dissection. ${ }^{7,8}$ Drainage of the CSF via a lumbar catheter, although frequently performed during aortic surgery for patients at high risk for spinal cord ischemia, has not been widely studied as a treatment option for aortic dissection accompanied by paraplegia. ${ }^{9}$ Previously published case reports have shown a benefit of this procedure in such patients. ${ }^{10}$ The rationale for such an intervention would be the increase in spinal cord perfusion pressure (spinal cord arterial pressure, or CSF pressure) as a consequence of CSF drainage. Despite the lack of recommendations or randomized controlled trials regarding this approach, it proved useful in this case, leading to an impressive neurological improvement during follow-up.

The case reported here highlights the importance of including aortic dissection in the differential diagnosis of acute paraplegia, even in the presence of an entirely normal cardiovascular examination. In addition, the outcome was favorable after CSF drainage, a procedure not routinely indicated in this scenario.

\section{REFERENCES}

1. Hagan PG, Nienaber CA, Isselbacher EM, et al. The International Registry of Acute Aortic Dissection (IRAD): new insights into an old disease. JAMA. 2000;283(7):897-903. http://dx.doi.org/10.1001/jama.283.7.897

2. Park SW, Hutchison S, Mehta RH, et al. Association of painless acute aortic dissection with increased mortality. Mayo Clin Proc. 2004;79(10):1252-7. PMid:15473405. http://dx.doi.org/10.4065/79.10.1252

3. Joo JB, Cummings AJ. Acute thoracoabdominal aortic dissection presenting as painless, transient paralysis of the lower extremities: a case report. J Emerg Med. 2000;19(4):333-7. http://dx.doi.org/10.1016/S0736-4679 (00)00264-X

4. Donovan EM, Seidel GK, Cohen A. Painless aortic dissection presenting as high paraplegia: a case report. Arch Phys Med Rehabil. 2000;81(10):1436-8. PMid:11030513. http://dx.doi.org/10.1053/apmr.2000.7158

5. Cheshire WP, Santos CC, Massey EW, Howard JF Jr. Spinal cord infarction: etiology and outcome. Neurology. 1996;47(2):321-30. PMid:8757000.

6. Wilmshurst JM, Walker MC, Pohl KR. Rapid onset transverse myelitis in adolescence: implications for pathogenesis and prognosis. Arch Dis Child. 1999;80(2):137-42. PMid:10325728. PMCid:1717819. http://dx.doi.org/10. 1136/adc.80.2.137

7. Erbel R, Alfonso F, Boileau C, et al. Diagnosis and management of aortic dissection. Eur Heart J. 2001;22(18):1642-81. PMid:11511117. http://dx.doi.org/10.1053/euhj.2001.2782

8. Hiratzka LF, Bakris GL, Beckman JA, et al. Guidelines for the diagnosis and management of patients with thoracic aortic disease: a report of the American College of Cardiology Foundation, American Heart Association Task Force on Practice Guidelines, American Association for Thoracic Surgery, American College of Radiology, American Stroke Association, Society of Cardiovascular Anesthesiologists, Society for Cardiovascular Angiography and Interventions, Society of Interventional Radiology, Society of Thoracic Surgeons, and Society for Vascular Medicine. Circulation. 2010;121(3):e266-e369. PMid:20233780. http://dx.doi.org/10.1161/CIR.0b013e3181d4739e

9. McGarvey ML, Cheung AT, Szeto W, Messe SR. Management of neurologic complications of thoracic aortic surgery. J Clin Neurophysiol. 2007;24(4):336-43. PMid:17938602.

10. Blacker DJ, Wijdicks EFM, Ramakrishna G. Resolution of severe paraplegia due to aortic dissection after CSF drainage. Neurology. 2003;61(1):142-3. PMid:12847182. 


\section{Conflict of interest: None}

Submitted on: $30^{\text {th }}$ November 2011

Accept on: $12^{\text {th }}$ January 2012

Correspondence: Divisão de Clínica Médica

Av. Prof. Lineu Prestes, 2565 - Cidade Universitária - São Paulo/SP - Brazil

CEP: 05508-000 - Phone: +55 (11) 3091-9200

E-mail: msbittencourt@bol.com.br 